\title{
A practical method for construction of $p-y$ curves for liquefiable soils
}

\section{S.R. Dash ${ }^{1}$, M. Rouholamin ${ }^{2}$ and S. Bhattacharya ${ }^{3}$}

${ }^{1}$ Assistant Professor, Indian Institute of Technology Bhubaneswar, India

${ }^{2}$ Research Fellow, University of Surrey, UK

${ }^{3}$ Chair in Geomechanics, University of Surrey, UK

Corresponding author: Professor Subhamoy Bhattacharya, University of Surrey, GU2 7XH, Phone: 01483 689534;

Email: S.Bhattacharya@ surrey.ac.uk

\begin{abstract}
In practice, analysis of laterally loaded piles are carried out using "Beam on Non-linear Winkler Foundation" method whereby the lateral pile-soil interactions are modelled as a set of springs defined by backbone curves (also known as $p-y$ curves). During seismic liquefaction, the saturated sandy soil changes its state from a solid to a thick fluid like material (solid suspension), which in turn alters the shape of the $p-y$ curve. Typically, the $p-y$ curve for non-liquefied soil looks like a convex curve with initial stiff slope which reduces with $y$. However, recent research conclusively showed that $p-y$ curve for liquefied soil has a completely different shape, i.e., upward concave with near-zero initial stiffness (due to the loss of particle to particle contact) up to a certain displacement $(y)$, beyond which the stiffness increases due to re-engaging of the sand particles. This paper presents a stepwise practical method for construction of $p-y$ curves with an example.
\end{abstract}

Key words: p-y curves, liquefied soil, pile-soil interaction, BNWF model

\subsection{Introduction}

A reasonably representation of pile-soil interaction is important in the evaluation of response of pile foundation to earthquake loads. Winkler approach (also known as Beams on Non-Linear Winkler Foundation, BNWF) for analysis of laterally loaded pile is widely used in the practice due to the ease of modelling nonlinearity and also mathematical and computational efficiency. Figure-1 (a) schematically demonstrates the BNWF model where the lateral, axial and end bearing soil-pile interactions are modelled by lateral springs ( $p-y$ spring), axial springs $(t-z$ spring) and end-bearing spring $(q-z$ spring), respectively. For evaluating the lateral capacity of pile foundation, $p-y$ spring plays a vital role, and the backbone force deformation behaviour defined for this spring is known as $p-y$ curve. In a $p-y$ curve, $p$ is the soil reaction per unit length of the pile and $y$ is the corresponding relative pile-soil displacement. For liquefied soil, the $p$ - $y$ curve used in current practice is a factored value from its non-liquefied state, which is found to be in disagreement with the $p-y$ curve observed from many full scale, centrifuge and shaking table tests (Dash, 2010). Figures 1(b) and 1(c) shows the shape of $p-y$ curves in pre and post-liquefaction stage based on the recent studies reported in Lombardi et al. (2017). Further details of the shape of the $p-y$ curves for liquefied and non-liquefied soils can be found in Bhattacharya et al. (2009), Dash (2010), Lombardi and Bhattacharya (2016). Bouzid et al. (2013) noted that the shape of $p$ - $y$ curves should follow stress-strain of the soil and it may be noted that the shape of $p-y$ curves for liquefied soil shown in Figure 1(c) is consistent with the stress strain of liquefied soil, see Dash (2010), Lombardi et al. (2014), Rouholamin et al. (2017). In particular, near zero initial slope is observed in both stress-strain curve and $p-y$ curves. Essentially, when liquefied soil is subjected to monotonic shearing, it needs some displacement for sand particle to re-lock together. Lombardi et al. (2017) provides the basis of $p$ $y$ curve for liquefied soil and its validation in line with the above concept. The aim of the paper is to present a step-bystep guide for constructing $p-y$ curves for liquefiable soils based on standard soil parameters.

\subsection{Major Steps in the Construction of $\boldsymbol{p}-\boldsymbol{y}$ Curves for Liquefiable Soils}

The construction of $p-y$ curves for liquefiable soils involves four major steps, as discussed below.

1) Evaluation of soil parameters from bore-log information

2) Consideration of dimensions of pile foundations

3) Construction of simplified stress-strain curve for liquefied soil

4) Preparation of $p-y$ curve for liquefied soil from stress-strain curve evaluated in step 3 above.

\subsection{Evaluation of Soil parameters from bore-log data}

Normally the bore-log data from a site provides the variation of STP $(N)$ values with depth. However, some advanced soil properties are necessary to construct its $p-y$ curve if the soil in question is liquefiable. The soil parameters that are necessary are: corrected SPT value $\left(N_{l}\right)$, relative density $\left(D_{r}\right)$, critical state stress ratio $\left(M_{c}\right)$, and residual shear strength of liquefied soil $\left(S_{u}\right)$. These parameters can be estimated from element testing or else standard correlations can be used. This paper provides some standard correlations available in the literature those can be used in the absence of advanced soil properties. However, the limitations and applicability must be checked for the actual site condition in hand for the adopted correlations. Some typical correlations as per available literature are given below for reference.

(a) For sandy soil, the field SPT value can be corrected for overburden pressure as: 


$$
N_{1}=\left(N / \sqrt{\left(p_{i n i}^{\prime} / 98\right)}\right)
$$

where $p_{i n i}^{\prime}$ is the initial effective overburden pressure

(b) The relative density of the soil can be estimated using correlations available in the literature from SPT $N_{l}$ value. The relationship of $N_{l}$ and $D_{r}$ suggested by Curbinovski and Ishihara (1999) as follows may be used.

$D_{r}=\sqrt{N_{1} / C_{D}}$

Where $C_{D}=\left(9 /\left(e_{\max }-e_{\min }\right)\right)^{1.7}=20$ for sand with fines, $\mathrm{Fc} \approx 20 \%, 41$ for clean sand and 70 for Gravelly sand

(c) The critical state stress ratio $\left(M_{c}\right)$ for the soil can be estimated as

$M_{c}=\left[\left(6 \sin \varphi_{c s}\right) /\left(3-\sin \varphi_{c s}\right)\right]$

where, $\varphi_{c s}$ is the critical state angle of soil. When the value of $\varphi_{c s}$ is not available, this can approximately be derived by using Bowles (1996) Equation as: $\varphi_{c s}=28^{\circ}+15 D_{r} \pm 2^{\circ}$

(d) The residual shear strength of liquefied soil $\left(s_{u}\right)$ is defined as the shear strength mobilized at large deformation after liquefaction is triggered in saturated contractive sandy soils (Olson and Stark, 2002). There are many correlations available in the literature to specify the residual shear strength of liquefied soil, either based on SPT or CPT, initial effective overburden, etc. The upper and/or lower bound values are to be used to capture the worst possible response while analyzing lateral pile-soil interaction. Figure 2(a) can be referred for $s_{u}$ based on corrected SPT value.

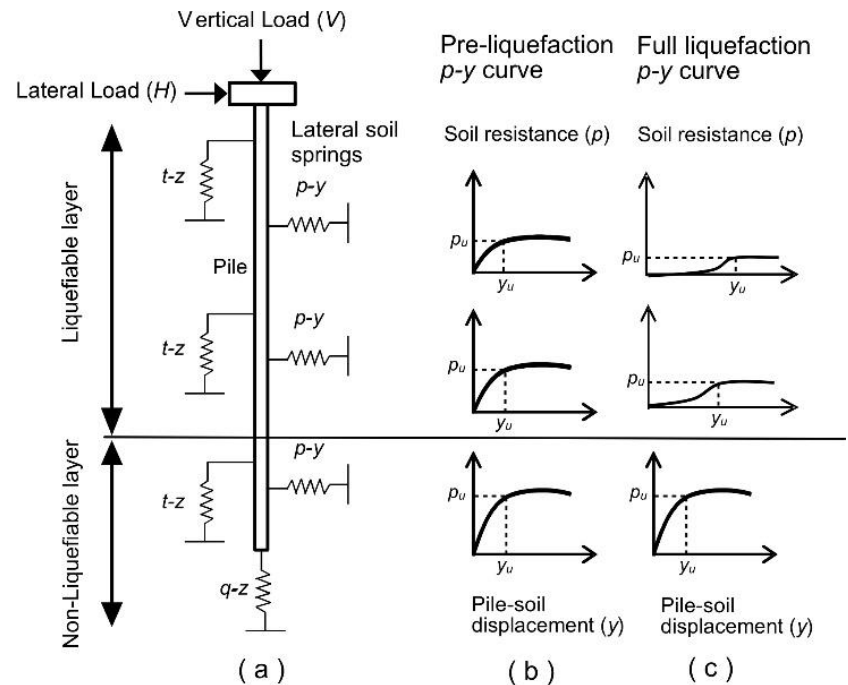

Figure 1: (a) BNWF model of pile-soil interaction, (b) pre liquefaction, and (c) post liquefaction $p-y$ curves

\subsection{Consideration of pile foundation data}

The pile diameter is a necessary parameter for $p-y$ curve construction. The friction between pile and soil will influence the soil resistance to pile displacement with rough pile-soil interface providing more resistance than smooth interface. Depending on the pile material, the interface shall be classified either smooth or rough. Typically, concrete pile interface is considered as rough and steel pile as smooth. Another parameter that is needed for p-y curve construction is an estimate of the shear strength of soil which dictates wedge failure (at shallow depth) or flow failure (at deeper depths). This difference in behaviour can be estimated based on the graph shown in Figure 2(b) using a critical ratio $(\beta)$ defined by the ratio of depth to diameter. This critical depth concept is taken from API (2010) and is a function of relative density or angle of friction. For the soil at particular depth $(h)$ and for the pile diameter $D$, if $(h / D)$ is greater than $\beta$, then the soil can be considered to be at deeper depth, else at shallow depth.

\subsection{Construction of simplified stress-strain curve for liquefied soil}

Unless element test on the soil is available and the stress-strain model in shear is developed, a simplified model as proposed below can be utilised for liquefied soil. This simplified model is defined using four parameters: (a) Take off strain $\left(\gamma_{t o}\right)$, Initial Shear Modulus $\left(G_{l}\right)$, Critical state shear modulus $\left(G_{2}\right)$ and ultimate shear strength $\left(\tau_{\max }\right)$. The correlations to find these four parameters are given in Figure-3. In figure $3, \tau_{\max (d)}$ corresponds to minimum possible non negative pore water pressure in post liquefaction shearing and $\tau_{\max (s)}$ corresponds to residual shear strength of soil at shallow depth. 

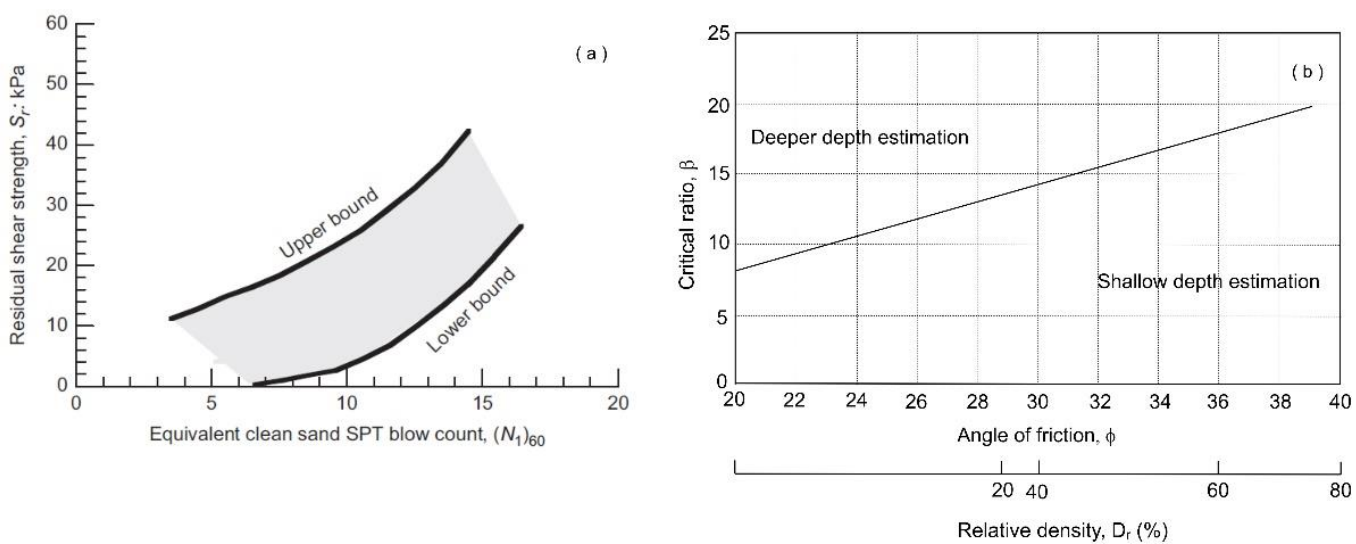

Figure 2: (a) Residual shear strength of liquefied soil (after Cubrinovski and Bradley, 2008) and (b) Critical depth ratio $(\beta)$ for various relative density/angle of friction
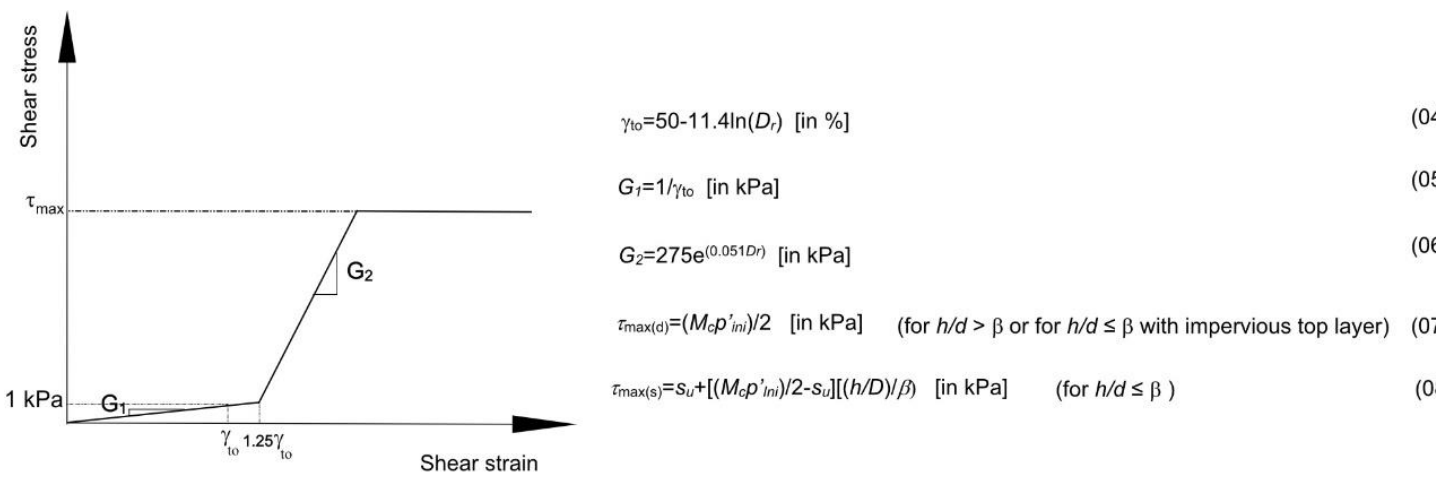

Figure 3: Post liquefaction stress-strain parameters for liquefied soil

For evaluation of $\gamma_{t o}$ and $G_{2}$ extensive element test results were considered for 9 different types of sand such as Redhill110, Japanese silica sand No. 8, Ganga sand, and Assam sand (Rouholamin et al. 2017), Toyoura sand (Lombardi et al., 2014), Fraser River sand (Vaid and Thomas, 1995), Syncrude sand (Sivathayalan 1994), Narita sand (Yasuda et al., 1994), and Nanjing sand (Hua et al. 2011). The results are presented in Figure 4 where the post-liquefaction parameters are plotted against Relative density. Detailed discussion on these parameters are presented in Lombardi et al. (2017) and Rouholamin et al. (2017). Only in the absence of element test data these empirical relationships may be used to estimate stress-strain curve parameters for liquefied soil. It may be noted that the equations are based on experimental values for relative density range 20 to 80 and may not be extrapolated beyond the considered relative density ranges.

\subsection{Preparation of p-y curve for liquefied soil from stress-strain curve.}

Once the simplified stress-strain model of liquefied soil is formulated, the corresponding $p-y$ curve parameters are calculated by using scaling factors, $M_{s}$ and $N_{s}$ (see Dash, 2010, Bouzid et al. 2013 and Lombardi et al. 2017 for the derivation of these factors). Figure-5 schematically represents the process involved in preparing stress-strain model to the p-y curve of liquefied soil.
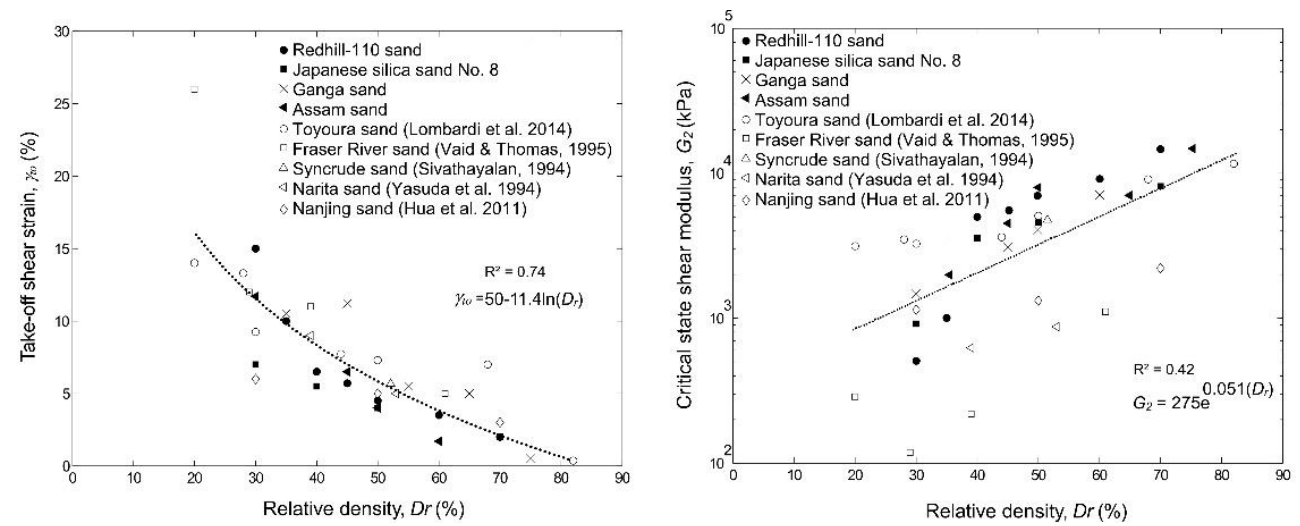

Figure 4. The effect of the soil Relative density on (a) take-off shear strain and (b) Critical state shear modulus $G_{2}$ 

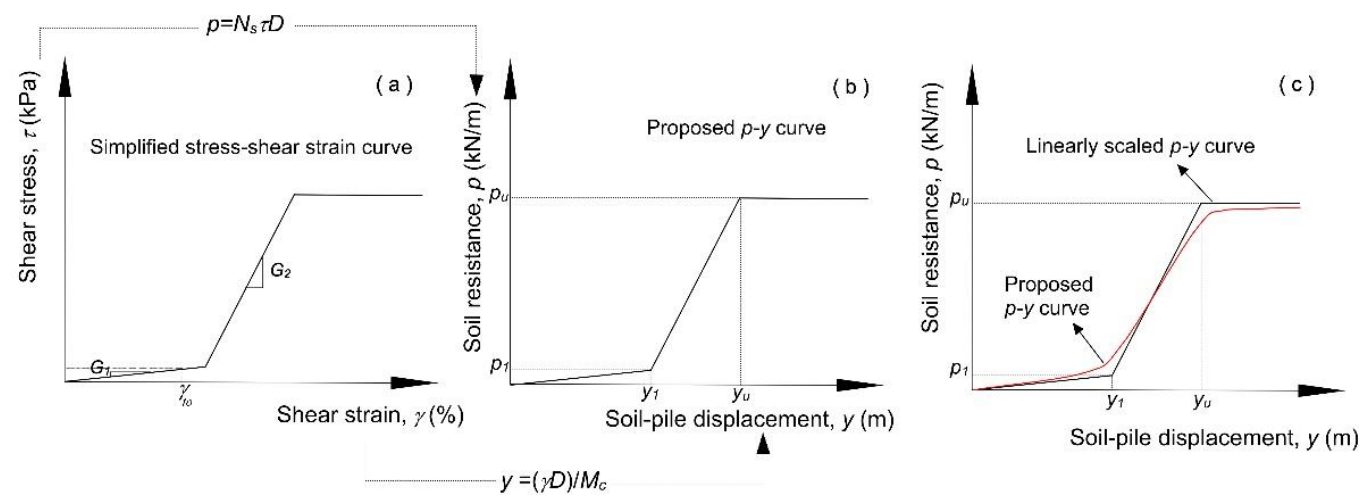

Figure 5: Schematic representation of obtaining p-y curve. (a) Simplified stress-strain curve for liquefied soil, (b) linearly scaled p-y curve model for stress-strain model, and (c) smoothed p-y curve model.

(a) The scaling factor $N_{s}=9.2$ for smooth interface and 11.94 for rough interface.

(b) The strain scaling factor $M_{s}=1.87$ for fully liquefied soil

(c) The initial lateral resistance corresponding to take-off strain $=p_{1}=N_{s} 1.25 \gamma_{t o} G_{1} D$

(d) The initial lateral displacement corresponding to take-off strain $=y_{1}=\frac{1.25 \gamma_{t o} D}{M_{s}}$

(e) The ultimate lateral resistance $p_{u}=N_{s} \tau_{\max } D$

(f) The ultimate lateral displacement $=y_{u}=\left(1.25 \gamma_{t o}+\frac{\tau_{\max }-\left(G_{1} 1.25 \gamma_{t o}\right)}{G_{2}}\right) \times \frac{D}{M_{s}}$

(g) To make the $p-y$ curve model effective in the numerical analysis and to represent the behaviour in a pragmatic way, the $p-y$ curve obtained in the above step is smoothened at its transition using weighing factors. The smooth $p-y$ relationship can be obtained by using the following expression.

$$
p=\omega \frac{p_{1}}{y_{1}} y+A(1-\omega)\left[\frac{p_{u}+p_{1}}{2}+\frac{p_{u}-p_{1}}{2} \tanh \frac{2 \pi}{3\left(y_{u}-y_{1}\right)}\left(y-\frac{y_{u}+y_{1}}{2}\right)\right]
$$

Where $A=0$ for $y=0$, and $\mathrm{A}=1$ for $y \neq 0$ and $\omega$ is a weight function as given equation 16 .

$$
\omega=\frac{1}{2}\left[1-\tanh \left(\frac{6 \pi}{y_{u}}\left(y-\frac{4 y_{1}+y_{u}}{6}\right)\right)\right]
$$

\subsection{Example for calculating $p-y$ curves for liquefied soil from a typical ground profile:}

Typically for onshore practice, SPT N value are obtained by the Client. Figure 6 (a) shows the ground profile along with a pile for which $p-y$ curves are constructed. Stepwise description is given below to obtain $p-y$ curves for liquefied soil for the depth of $5 \mathrm{~m}$, which can be extended for various depth of consideration.

\section{Steps to obtain p-y curve for liquefied soil from ground profile:}

Step - 1: The soil considered at a depth of $5 \mathrm{~m}$ with SPT value $=N=5$ and unit weight $=17 \mathrm{kN} / \mathrm{m}^{3}$

(a) The SPT value corrected for overburden $=N_{1}=8$, using Equation 1.

(b) The effective initial overburden $=p_{i n i}^{\prime}=5 \times(17-9.81)=36 \mathrm{kN} / \mathrm{m}^{2}$

(c) The relative density of soil $=D_{r}=0.45=45 \%$, by using Equation 2, considering it as clean sand

(d) The critical state stress ratio $=M_{c}=1.4$ by using Equation 3 where $\varphi_{c s}=28^{\circ}+15 D_{r}=34.7^{\circ}$

(e) For $N_{l}=8$, the residual strength $=s_{u}=1 \mathrm{kPa}$ (lower bound) and $19 \mathrm{kPa}$ (upper bound) using Figure 2(a)

Step-2: Considering the pile diameter as $0.6 \mathrm{~m}$, and pile material as steel

(a) The height to diameter ratio $=h / D=5 / 0.6=8.33$

(b) The critical depth ratio $=\beta=15$, obtained from Figure 2(b) for $D_{r}=45 \%$

Step - 3: For the considered soil and pile properties

(a) Take off strain $=\gamma_{t o}=6.6 \%=0.066$ for $D_{r}=45 \%$ using Equation 4

(b) Initial shear modulus $=G_{1}=15.14 \mathrm{kPa}$ using Equation 5

(c) Critical state shear modulus $=G_{2}=2609 \mathrm{kPa}$ using Equation 6 
(d) As $h / D<\beta$, and there is no impervious layer above, the strength calculation shall be governed by shallow depth formulation.

(e) For $\frac{h / D}{\beta}=\frac{8.33}{15}=0.56$, the ultimate shear strength of liquefied soil as per Equation 7

$$
\begin{aligned}
\tau_{\max }=s_{u}+\left(\frac{M_{c} p^{\prime}{ }_{i n i}}{2}-s_{u}\right) \frac{h / D}{\beta} & =1+\left(\frac{1.4 \times 36}{2}-1\right) 0.56=14.31 \mathrm{kPa} \text { (Lower bound) } \\
& =19+\left(\frac{1.4 \times 36}{2}-19\right) 0.56=22.41 \mathrm{kPa} \text { (Upper bound) }
\end{aligned}
$$

Step-4: From the estimated simplified stress-strain curve, the $p-y$ curve parameters are calculated as:

(a) The scaling factor for stress $N_{s}=9.2$ (considering smooth interface for steel pile)

(b) The scaling factor for strain $M_{s}$ is 1.87 for fully liquefied soil.

(c) $p$ - $y$ curve parameters using equations 11-14 are:

$p_{1}=6.9 \mathrm{kPa}$ and $y_{l}=27.5 \mathrm{~mm}, p_{u}=80 \mathrm{kN} / \mathrm{m}$ and $y_{u}=28.1 \mathrm{~mm}$ (Lower Bound)

$p_{1}=6.9 \mathrm{kPa}$ and $y_{1}=27.5 \mathrm{~mm}, p_{u}=124.1 \mathrm{kN} / \mathrm{m}$ and $y_{u}=29.1 \mathrm{~mm}$ (Upper Bound)

(d) The smooth $p$ - $y$ curve is obtained using Equation 15.

The above calculation enables to plot the $p-y$ curve at $5 \mathrm{~m}$ depth, for both lower bound and upper bound condition as shown in Figure 6(b). Similar calculation can be also done for various depths be used for static or pseudo static analysis of pile foundation in liquefiable soils in a BNWF model.

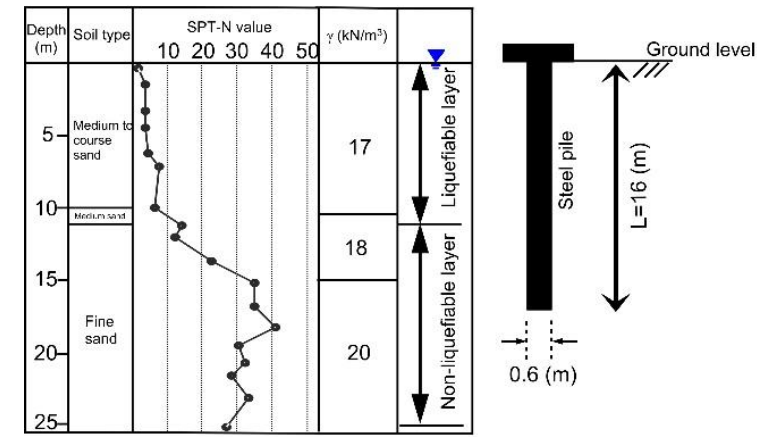

(a)

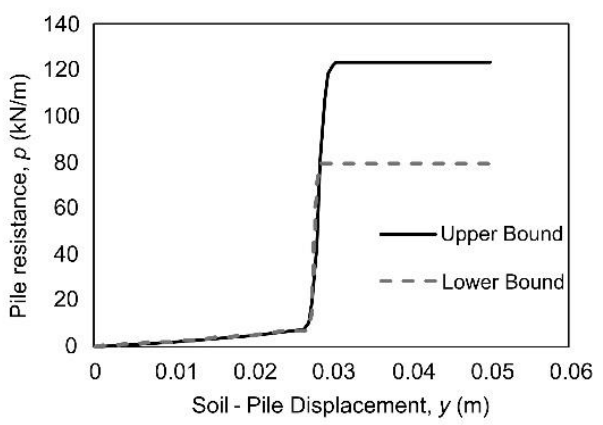

(c)

Figure 6: (a) Soil profile with SPT N-value at the site along (b) pile details, (c) $p-y$ curve for liquefied soil layer at $5 \mathrm{~m}$.

\section{Conclusion:}

In this paper a practical method for construction of $p-y$ curves for liquefiable soils is discussed. A step by step calculation has been provided with an example considering standard bore log data. The calculation uses basic soil properties like field density and SPT value at various depth and basic pile data like size and material. Further advanced soil properties are estimated using empirical relationships. Once the stress-strain behaviour of post-liquefied soil is defined, the $p$ - $y$ curve has been constructed using scaling factors. This $p-y$ curve captures the basic form and mechanics of liquefied soil and expected to be very useful while carrying out soil-pile interaction study in liquefiable soils.

\section{References:}

Bhattacharya S, Adhikari S, Alexander NA. (2009) Simplified method for unified buckling and dynamic analysis of pile supported structures in seismically liquefiable soils. Soil Dynamics and Earthquake Engineering; 29:1220-1235. DOI:10.1016/jsoildyn.2009.01.006.

Dash (2010), Lateral Pile Soil Interaction in Liquefiable Soils, PhD Thesis, University of Oxford

Lombardi, D., and Bhattacharya, S. (2016) Evaluation of seismic performance of pile-supported models in liquefiable soil. Earthquake Engineering and Structure Dynamics; 45:1019-1038.

Lombardi, D., Dash, SR., Bhattacharya, S., Ibraim, E., Wood, DM., Taylor, CA., (2017). Construction of simplified design p-y curves for liquefied soils. Geotechnique. http://dx.doi.org/10.1680/igeot.15.P.116

Bouzid, DJ., Bhattacharya, S., \& Dash, SR. (2013). Winkler Springs (p-y curves) for pile design from stress-strain of soils: FE assessment of scaling coefficients using the Mobilized Strength Design concept. Geomechanics and Engineering 5(5): pp.379399.

Lombardi, D., Bhattacharya, S., Hyodo, M. \& Kaneko, T. (2014). Undrained behaviour of two silica sands and practical implications for modelling SSI in liquefiable soils, Soil Dynamics and Earthquake Engineering 66, $293-304$.

Rouholamin, M., Bhattacharya, S., and Orense, R. (2017). Effect of initial relative density on the post-liquefaction of sand. Soil Dynamics and Earthquake Engineering. In press.

American Petroleum Institute (2011). Recommended practice for planning, designing and constructing fixed offshore platforms-Load and resistance factor design, API-RP-2A, 21st Edition. 
Bowles, JE. (1996). Foundation analysis and design. Fifth edition. The McGraw-Hill Companies, Inc. New York.

Stark, T.D., and Mesri, G. 1992. Undrained shear strength of liquefied sands for stability analysis. Journal of Geotechnical Engineering, ASCE, 118(1 I): 1727-1747.

Olson, S.M. and Stark, T.D. 2002. Liquefied strength ratio from liquefaction flow failure case studies. Canadian Geotechnical Journal. 39(3). 629-647.

Vaid, Y. \& Thomas, J. (1995). Liquefaction and post liquefaction behaviour of sand. Journal of Geotechnical Engineering 121(2), 163-173.

Sivathayalan (1994). Static cyclic and post liquefaction simple shear response of sands, MSc Thesis, University of British Columbia.

Yasuda, S., Masuda, T., Yoshida, N., Nagase, H., Kiku, H., Itafuji, S., Mine K. and Sato, K. (1994). Torsional shear and triaxial compression tests on deformation characters of sands before and after liquefaction. Proc., 5th US-Japan workshop on earthquake resistant design of lifelines and countermeasures against soil liquefaction. 249-265

Pan Hua, Chen Guoxing, Liu Hanlong and Wang Binghui (2011). Behavior of large post-liquefaction deformation in saturated Nanjing fine sand, Earthquake engineering and engineering vibration, Vol.10, No.2, pp. 187-193.

Cubrinovski, M. and Ishihara, K. (1999). Empirical Correlation between SPT N value and relative density for sandy soils. Soil and Foundation, Japanese Geotechnical Society, Vol. 39, No.5, pp. 61-71. 